\title{
Measuring dynamic effects on underpasses of high-speed railway lines
}

\author{
Jaime Vega , Lutz Hermanns, Enrique Alarcon and Alberto Fraile
}

\section{Introduction}

The analysis of the dynamic response of bridges traversed by moving loads has a long tradition in civil engineering. Since the first contributions of Inglis (1934), Stokes (1867), Timoshenko (1911) and Willis (1849), to cite just a few, numerous authors and institutions have contributed to this topic. With the introduction of the digital computer, it became possible to analyse more complicated problems (Biggs, 1964; Fryba, 1972; Hillerborg, 1951).

Those studies and the improvement of equipment for in situ tests drove the Union Internationale des Chemins de Fer (UIC) to promote a research programme (Question D23) conducted by its Office de Recherches et Essais (ORE), trying to find a formula for the so-called impact coefficient. This programme was completed around 1970 proposing a stress increment on the static maximum one that was dependent on both the maximum static stress and the bridge span length (ORE, 1970).

At the same time, other research projects were launched taking advantage of new computational advances. For example, the one trying to fix the bridge flexibility assuring suitable comfort levels for passenger (Question D160), in which moving finite elements were used (Alvarez, Molina, Doblare \& Alarcon, 1990). The conclusions of question D23 apparently closed the problem, or at least, from a practical point of view.

With the introduction of commercial high-speed lines (HSLs), it was observed that short span bridges displayed important accelerations. The excessive vibrations led to a rapid deterioration of track quality and some damage on some short span structures of the Paris Lyon line (Zacher \& Baessler, 2005). This experience showed that, in addition to safety problems due to insufficient contact, high accelerations may also lead to higher costs due to shorter regulation cycles in order to ensure track geometry. Those problems were analysed with the power of the new computational methods and electronic equipment for in situ testing. In particular, during the 1990 s, several expressions were obtained for the impact coefficient, and further studies focused on the maximum vertical accelerations (UIC, 1994).

The standard reference is the one from the European Rail Research Institute (ERRI-D214, 1999), but it has also been used by other authors (Yang \& Yau, 1997). It was observed that short-span bridges, i.e. less than $15 \mathrm{~m}$ (Sorgofrei \& Marianos, 2000 ), were very sensitive to high-speed trains (Museros, Romero, Poy, \& Alarcon, 2002). In this context the otherwise efficient and economic frame structures 
come out to be specially well suited. The dissipative capacity of their backfill increases the global damping and consequently reduces the bridge response.

The distinction between culverts and short-span bridges was not clear, and a concern was raised regarding whether culverts were affected by the new speeds. It is interesting to note that underpasses are often used. Railway networks run long distances with very restrictive geometric constraints (e.g. gradients, alignment, curvature and radius), thus making crossing through a large variety of topographical difficulties unavoidable. Culverts are used for a large variety of crossings, including drainage conducts, wildlife corridors and roads of low and medium importance underpasses.

The same situation applies to roads. It is often cited that there are 575 thousand bridges over $6 \mathrm{~m}$ long in the National Bridge Inventory, in the US. However, it is seldom mentioned that 100 thousand of them are culverts (Barker \& Puckett, 1997). In general, these small infrastructures have never been considered worth an in-depth structural analysis, except for the so-called soil-steel bridges (AbdelSayed, Bakht, \& Jaeger, 1994; TRB, 1985), where the flexibility of the conduit wall presents an interesting challenge to the designer from the viewpoint of soilstructure interactions. When concrete is used, the design is often executed in a routine fashion. Designers may forget that although the individual cost is low, the large number of culverts on a typical HSL makes the avoidance of any structural problems and the reduction of maintenance costs an economically worthwhile objective.

The dynamic analysis of the soil-structure interaction of a frame supporting an HSL is challenging, even from a purely scientific viewpoint. Therefore, guidelines (eventually a code) should be provided to designers to complement the existing Eurocodes, which state checks for stresses and fatigue, but also for maximum peak acceleration beneath the ballast (EN1990-A2, 1990; EN1991-P2 2002).

The research presented in this paper is a first step aiming at this goal. Several authors previously attempted to develop such a simplified design method using advanced boundary element methodology (Fraile, Hermanns, Chirino, \& Alarcon, 2002), but at that time, it was impossible to find published results reporting on site measurements against which to verify the theoretical results. For example, Ulker-Kaustell, Karoumi and Pacoste (2010) studied vertical accelerations for a portal frame and proposed a model based on finite elements, but their results could not be compared with any measurements. So it was deemed necessary to perform measurements on existing underpasses. The recently built HSL between Segovia and
Valladolid was selected for this purpose. In this study, comprehensive description of the measurements is presented. Also results are analysed revealing interesting aspects of the dynamic behaviour of this kind of partially buried structures. Parts of the measurements as well as some preliminary analysis have been presented elsewhere (Alarcon, Vega, Montañes, \& Fraile, 2010; Vega, Hermanns, Alarcon, \& Fraile, 2011).

First, we present the statistical analysis supporting the selection of the structures to be monitored. Next, acceleration records will be presented and discussed, with reference to a given structure. These results allow interesting conclusions about the dynamic behaviour of underpasses. Finally, maximum recorded values will be presented and analysed globally. The authors trust they will be useful for other researchers in the same field.

\section{Case study presentation: Segovia-Valladolid HSL}

\subsection{Geometric analysis of structures}

The HSL between Segovia and Valladolid, two historical cities of Old Castille, was completed in 2004 , and consists of a double track alignment along $91 \mathrm{~km}$. It includes 131 small concrete structures to allow passage of small streams, livestock, vehicles and pedestrians through railway embankments. This figure takes into account only structures at the main line (no branch lines), and therefore all of them support double tracks. It excludes both single span simply supported structures as well as multiple span structures. Their structural form varies among pipes (Figure 1a), open (without lower slab) moment-resisting frames (Figure 1b), plate arches (Figure 1c) and rigid-box frames (Figure 1d). There are 10, 7, 5 and 109 of them, respectively. Thus, the proportion of box-frames is overwhelming ( $83 \%$ of the total), with many of them totally precast.

A histogram representing the span length distribution for rigid-box frames is presented in Figure 2. It allows identifying three groups: around $3 \mathrm{~m}$, around $8 \mathrm{~m}$ and between 10 and $12 \mathrm{~m}$. The first one clusters almost all drainage conducts and livestock passages for amphibians and small mammals, but there are some extreme cases with spans reaching $6 \mathrm{~m}$. The other groups relate mainly to rural ways $(8 \mathrm{~m})$ and roads $(10$ to $12 \mathrm{~m}$ ), but crossings for large mammals also fall into the last group.

Other geometric parameters that may influence the dynamic behaviour of the structure have been analysed within each of the above-mentioned groups. Table 1 shows the ranges of variation of these quantities. It should be pointed out that, in railway lines, the depth of cover is measured between the culvert-crown and 


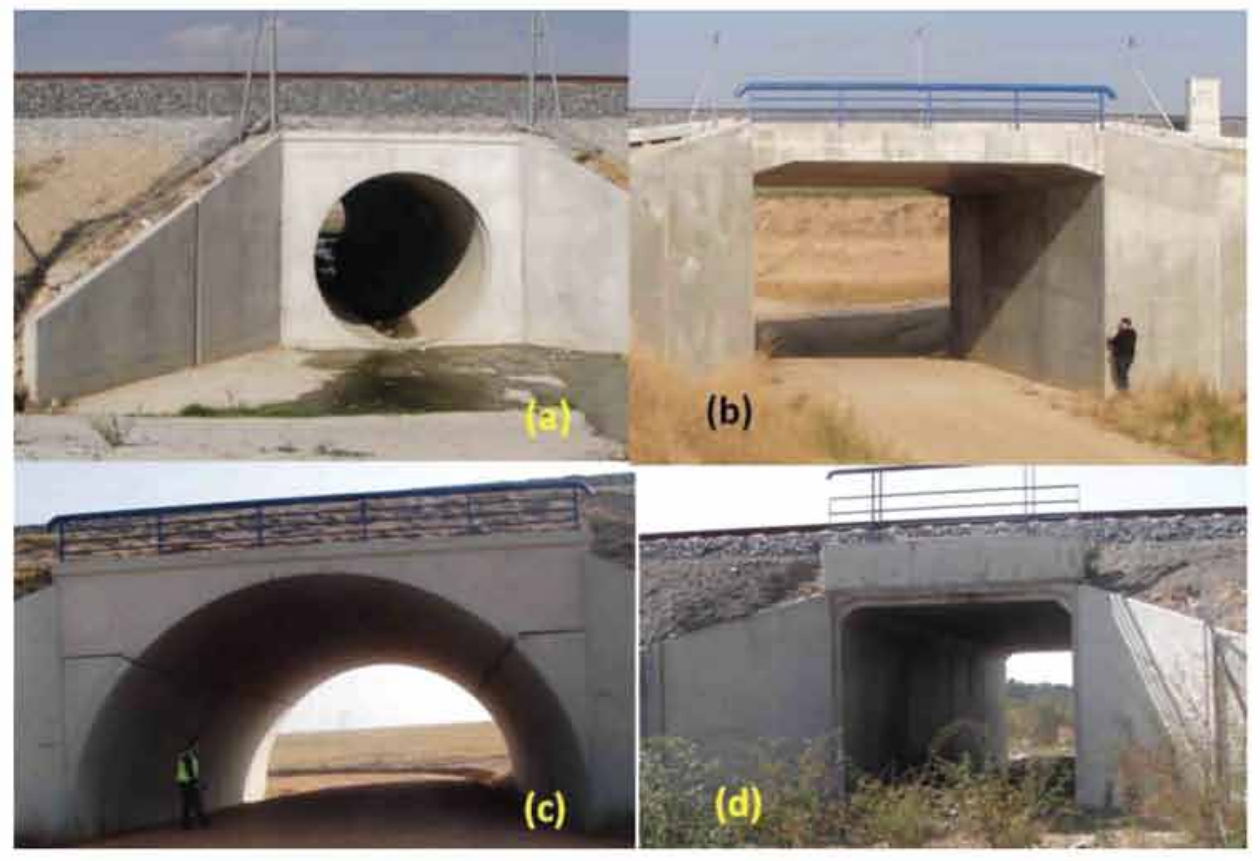

Figure 1. Structural typologies found: (a) pipes, (b) open moment-resisting frames, (c) plate arches and (d) rigid-box frames.

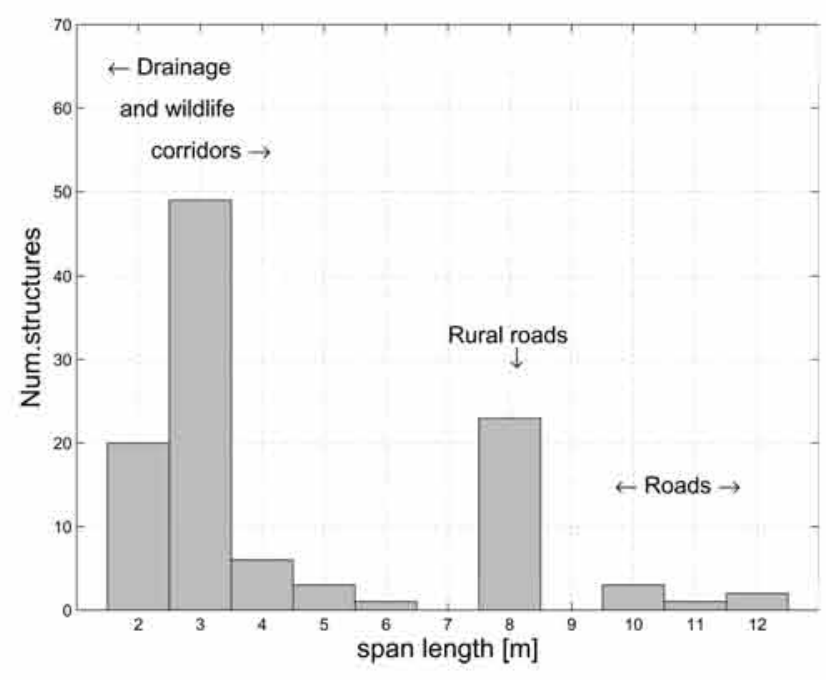

Figure 2. Span-length distribution for rigid-box frames.

Table 1. Dimensional characterisation of rigid-box frames clustered in three groups depending on their span.

\begin{tabular}{|c|c|c|c|c|c|c|c|c|}
\hline \multirow{2}{*}{$\begin{array}{l}\text { Span } \\
(\mathrm{m})\end{array}$} & \multicolumn{2}{|c|}{$\begin{array}{l}\text { Rise } \\
(\mathrm{m})\end{array}$} & \multicolumn{2}{|c|}{$\begin{array}{l}\text { Abut. } \\
\text { thickness (m) }\end{array}$} & \multicolumn{2}{|c|}{$\begin{array}{c}\text { Slab } \\
\text { thickness (m) }\end{array}$} & \multicolumn{2}{|c|}{$\begin{array}{l}\text { Depth of } \\
\text { cover }(\mathrm{m})\end{array}$} \\
\hline & Min. & Max. & Min. & Max. & Min. & Max & Min. & Max. \\
\hline & & 3 & 0.15 & 0 . & 0. & 0 & 0 . & 7 \\
\hline & 2.5 & 6. & 0.35 & 1. & 0 . & 1. & 0.4 & 3.5 \\
\hline $10-12$ & 4.8 & 5.5 & 0.45 & 0.95 & 0.9 & 1.2 & 1 & 9 \\
\hline
\end{tabular}

the ballast-embankment interface. The sketches of the two structures with their respective values of depth of cover are presented in Figure 4.

\subsection{Selection of structures for in situ testing}

Nine structures were selected for the project. The largest amounts (six) are rigid-box frames because they are the most abundant ones. Selection was further guided by span length, in order to cover a wide range of values. Their pictures are presented in Figure 3, and their geometrical characteristics are listed in Table 2.

The main criteria leading to the choice was covering the whole range of span lengths. Also it was decided to consider only structures with their own axes being almost perpendicular to the track's one. In addition to this, the overburden, or depth of cover, was limited to $2 \mathrm{~m}$. Stresses generated by the wheel-rail interaction loads are spread over a greater area by the layers between the track and the buried structure, so that the effects are reduced with the depth of cover. Some codes, such as the Spanish one (IAPF, 2007), allow neglecting those stresses beyond a $2 \mathrm{~m}$ limit distance. The limit value chosen for this study is consistent with the code one. Finally, the topological conditions of the surroundings were required to allow both suitable access and good visibility of the arriving train while conducting the tests. These multiple criteria are the reason for why the longest span is $10 \mathrm{~m}$ instead of $12 \mathrm{~m}$.

In order to asses the importance of the abovementioned limit, it was decided to select a second $3 \times 3 \mathrm{~m}$ frame, the new one being more deeply buried (cf. frame $m 038$ in Figure 3(c)). Figure 4 shows longitudinal cross sections of frames $m 023$ (Figure 


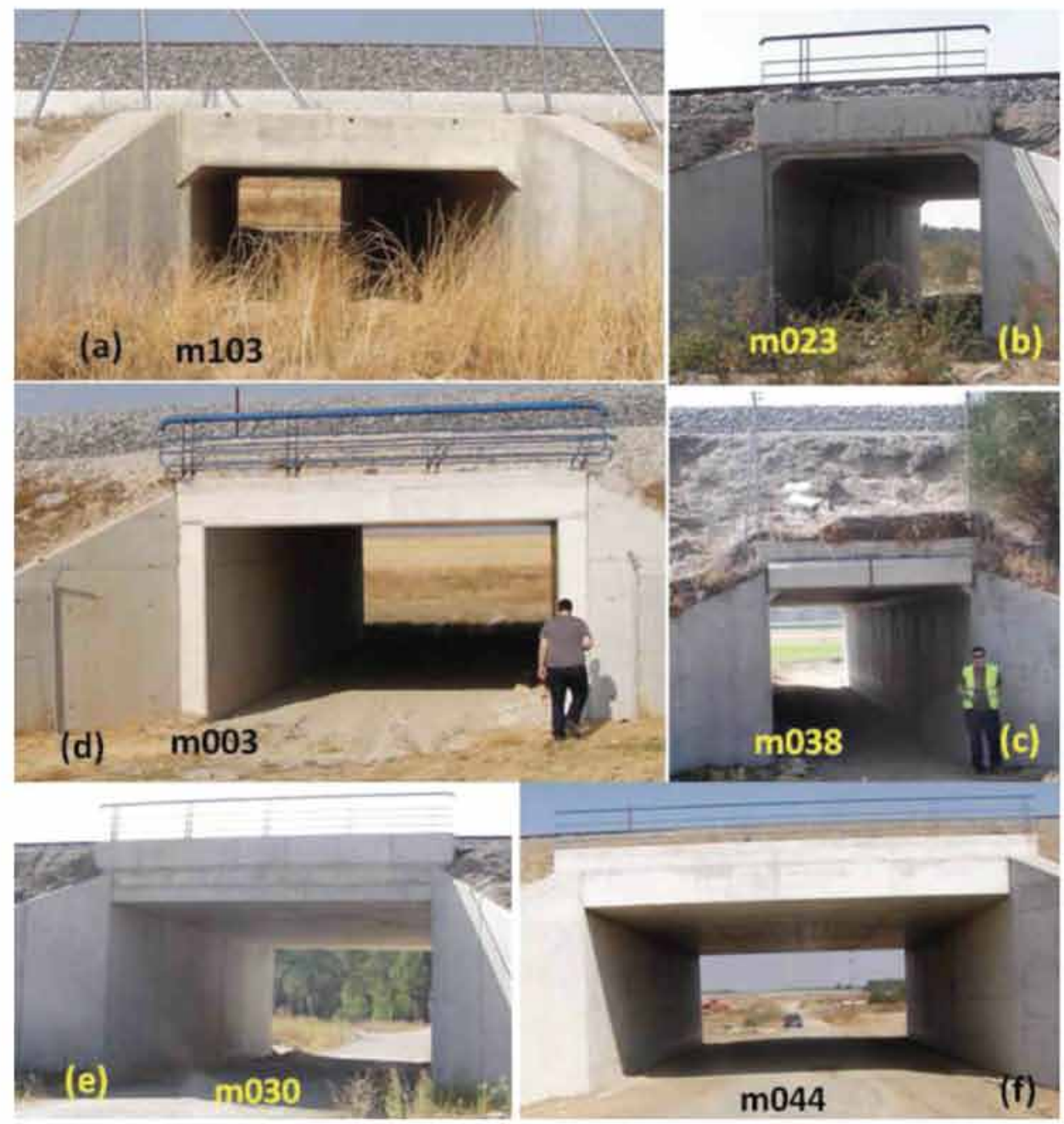

Figure 3. Photographs of selected box frames.
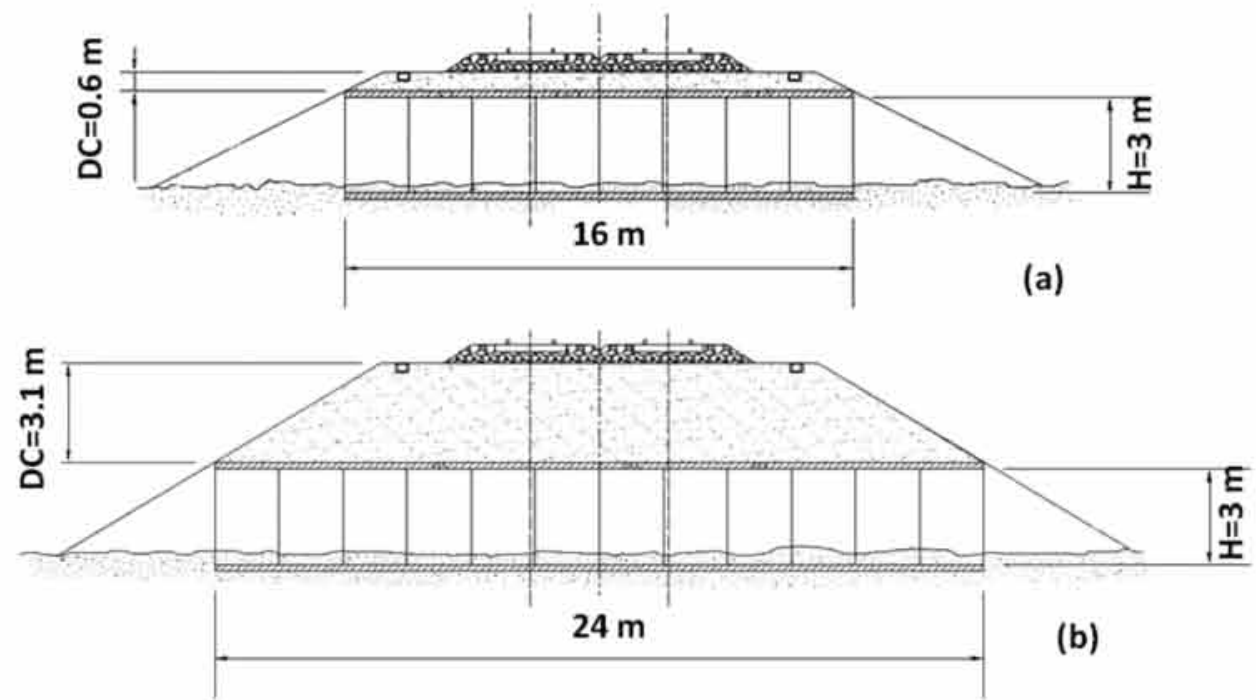

Figure 4. Longitudinal section of frames with $3 \times 3 \mathrm{~m}$ cross section: (a) $m 023$ and (b) $m 038$. 
4(a)) and $m 038$ (Figure 4(b)). It shows clearly that the underpass length depends on the depth of the cover.

\subsection{Additional comments on selected box-frames}

Concerning their construction method, samples m103, $\mathrm{m} 023$ and $\mathrm{m} 038$ are built using precast units $2 \mathrm{~m}$ long ( 9,8 and 12 units, respectively). Samples m003 and $\mathrm{m} 044$ are cast in situ. Sample $\mathrm{m} 030$ belongs to a mixed type where seven precast units $2.29 \mathrm{~m}$ wide were assembled including the whole side-walls and one half of the top slab, while the lower slab and the upper (compression) layer of the top one were cast in situ.

The line has been built mostly over sedimentary soils with standard penetration test (SPT) values higher than 30 under a shallow layer between 1 and $3 \mathrm{~m}$ depth. At all sites, the shallowest layer ( $1 \mathrm{~m}$ thick) of natural soil was removed, so that the actual shear wave celerity of the foundation soil can be assumed to vary between $150 \mathrm{~m} / \mathrm{s}$ for softer soils and $350 \mathrm{~m} / \mathrm{s}$ for stiffer ones. In addition, as shown in Figure 5, a granular bedding smooths the possible differential settlements and a selected standard backfill is carefully engineered behind the side-walls. Its mechanical characteristics are fixed by the owner (ADIF, 1998), and can be described as cemented gravel with very well specified properties.

\section{Monitoring scheme}

\subsection{Instrumentation}

Two levels of in situ testing were launched. Although the main interest was related to the dynamic response

Table 2. Geometrical characteristics of selected rigid boxframes.

\begin{tabular}{lccccc}
\hline Item & $\begin{array}{c}\text { Span, } \\
\mathrm{L}(\mathrm{m})\end{array}$ & $\begin{array}{c}\text { Rise, } \\
\mathrm{H}(\mathrm{m})\end{array}$ & $\begin{array}{c}\text { Depth. cover, } \\
\mathrm{DC}(\mathrm{m})\end{array}$ & $\mathrm{L} / \mathrm{H}$ & $\mathrm{DC} / \mathrm{L}$ \\
\hline$m 103$ & 2.3 & 1.5 & 0.6 & 1.53 & 0.26 \\
$m 023$ & 3 & 3 & 0.6 & 1.00 & 0.2 \\
$m 038$ & 3 & 3 & 3.1 & 1.00 & 1.03 \\
$m 003$ & 5 & 3 & 1.0 & 1.67 & 0.20 \\
$m 030$ & 8 & 4.75 & 1.0 & 1.68 & 0.13 \\
$m 044$ & 10 & 4.75 & 1.15 & 1.29 & 0.12 \\
\hline
\end{tabular}

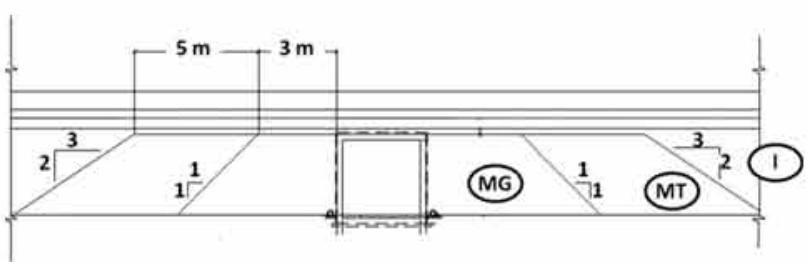

Figure 5. Longitudinal section of the embankment of sample structure $m 023$ displaying its various materials. of the concrete structure (basic level), it was also considered that some simultaneous measurements on the track could be useful (detailed level), and items $\mathrm{m} 023$ and $\mathrm{m} 030$ were selected for that purpose.

In all cases, the structure was instrumented with six sensors (cf. Figure 6(a)). Three of these sensors (Sensors A, B and C) recorded the vertical acceleration at the midline of the roof-slab, and three others (Sensors I, J and K) recorded the horizontal acceleration at the middle height of one side-wall. Sensors were placed without trying to establish any correspondence with the track centreline. Later, at office, during data screening and processing the transducer results were reinterpreted in relation with the track geometric placement as will be explained below.

As previously said, in the case of items $\mathrm{m} 023$ and m030, several accelerometers were placed on the rail and sleepers (cf. Figure 6(b)) in order to try to crosscheck levels of acceleration with previous experience. Also several experiments with an instrumented hammer were done in order to get transfer functions.

Several types of accelerometers were used: Endevco $7754 \mathrm{~A}-1000$ (sensitivity $1 \mathrm{~V} / \mathrm{g}$ ) at the roof-slab and side walls, $\mathrm{PCB} 352 \mathrm{C} 33$ (sensitivity $100 \mathrm{mV} / \mathrm{g}$ ) at the sleepers and PCB $352 \mathrm{C} 03$ (sensitivity $10 \mathrm{mV} / \mathrm{g}$ ) at the rails. The data acquisition system is NI DAQ-Pad 6015 , operating with a sampling rate of $f s=4096 \mathrm{~Hz}$ (anti-aliasing low-pass filter with cut-off frequency $1 \mathrm{kHz})$.

\subsection{Trains travelling the line}

This line is used by four different types of high-speed trains. Their nominal axle loads and distances are presented in Figure 7. The commercial names linked to RENFE (Spanish operator) codes and maximal speeds are listed in Table 3 . The so-called S-252 trains are quite different from the others because of their heavy locomotives. Although S-102 trains operate only on high-speed lines, the S-121 and S-130 trains have variable-width bogies, allowing them to use both the Spanish $(1667 \mathrm{~mm})$ and the UIC-gauge $(1435 \mathrm{~mm})$ networks. S-252 trains lay in between both cases: the carriages have variable-width, while the locomotives not, and need to be removed each time the train changes the network.

\section{Individual analysis}

In this section results from the on site measurements will be presented with reference to frame m023. Focus will be on features common to all structures, while differences will be analysed in the next section.

The sensor positions are shown in Figure 8. In the superstructure, the sensors were placed vertically on 


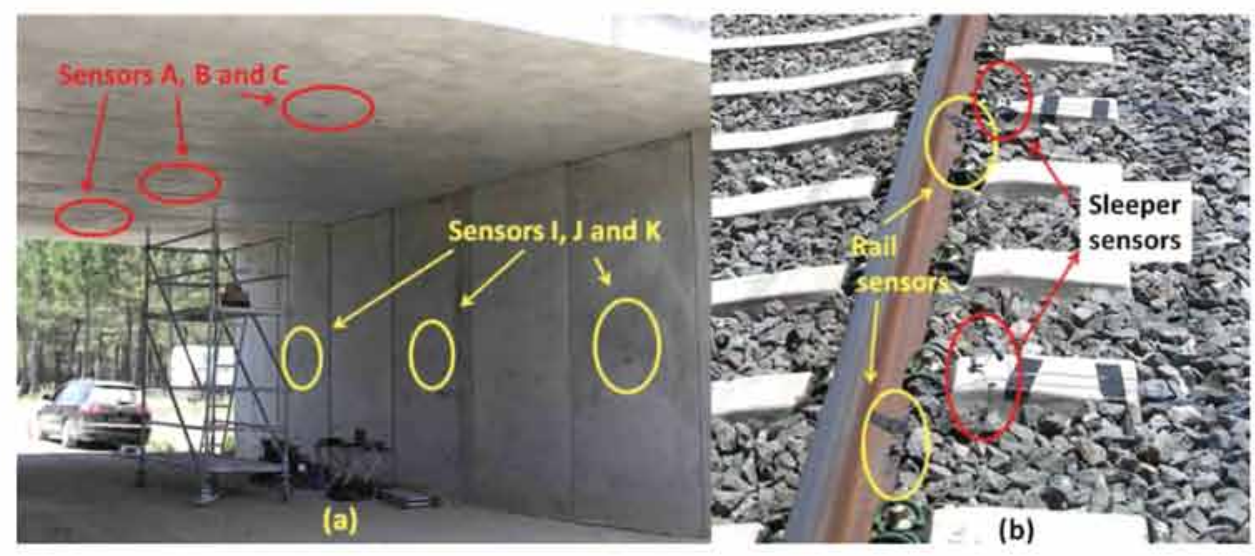

Figure 6. Sensor positioning in sample structure $m 030$ at: (a) the structure and (b) the superstructure.
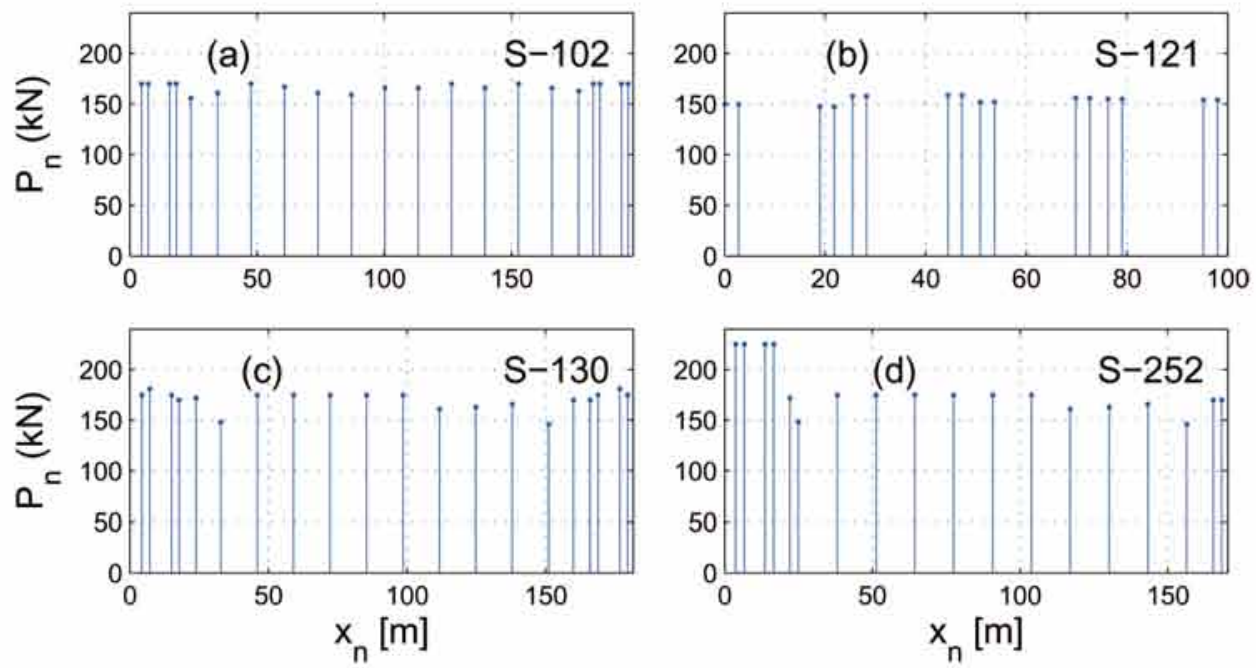

Figure 7. Axle loads and distributions for the four trains travelling the line: (a) S-102, (b) S-121, (c) S-130 and (d) S-252.

Table 3. Codes (commercial and RENFE) and maximum speeds for all observed train types.

\begin{tabular}{lrrrr}
\hline RENFE code & S-102 & S-121 & S-130 & \multicolumn{1}{c}{ S-252 } \\
\hline $\begin{array}{c}\text { Commercial } \\
\text { code }\end{array}$ & Talgo 350 & ATPRD & Talgo 250 & Talgo s-VII \\
$\begin{array}{c}\text { Max. speed } \\
(\mathrm{km} / \mathrm{h})\end{array}$ & 330 & 250 & 250 & 220 \\
\hline
\end{tabular}

the sleepers, close to the exterior rail-pads, and on the rail foot at midspan between two sleepers (cf. Figure 8). Four pairs of sleeper and rail sensors were placed, two on each track. In each track, one sensor was placed approximately over the midspan of the underpass, and the other one was placed three sleepers further towards the north (Valladolid).

A sample of the acceleration time histories obtained is shown in Figure 9. These data were recorded during the passage of an S-121 train in double configuration, with an estimated speed of 220 $\mathrm{km} / \mathrm{h}$. Speeds were estimated in two ways: from video recordings of the trains during the tests and by measuring the time lapses between peaks associated with each axle in the running root mean square (RMS) acceleration records. The acceleration records show important differences in measured levels depending on sensor position. In this case, the largest response was measured close to the roofslab centre (sensor B). Interestingly, sensor J, which is placed at the side-wall of the same precast block as sensor B, displays similar acceleration levels as sensor $\mathrm{A}$, which is placed at the roof-slab as sensor B.

A spectral analysis of this signal (cf. Figure 10) shows that the energy is distributed over a wide range between 0 and $120 \mathrm{~Hz}$ at the middle sensor position, and in a narrower range up to $60 \mathrm{~Hz}$ at the other two positions. The side-wall records also display important 


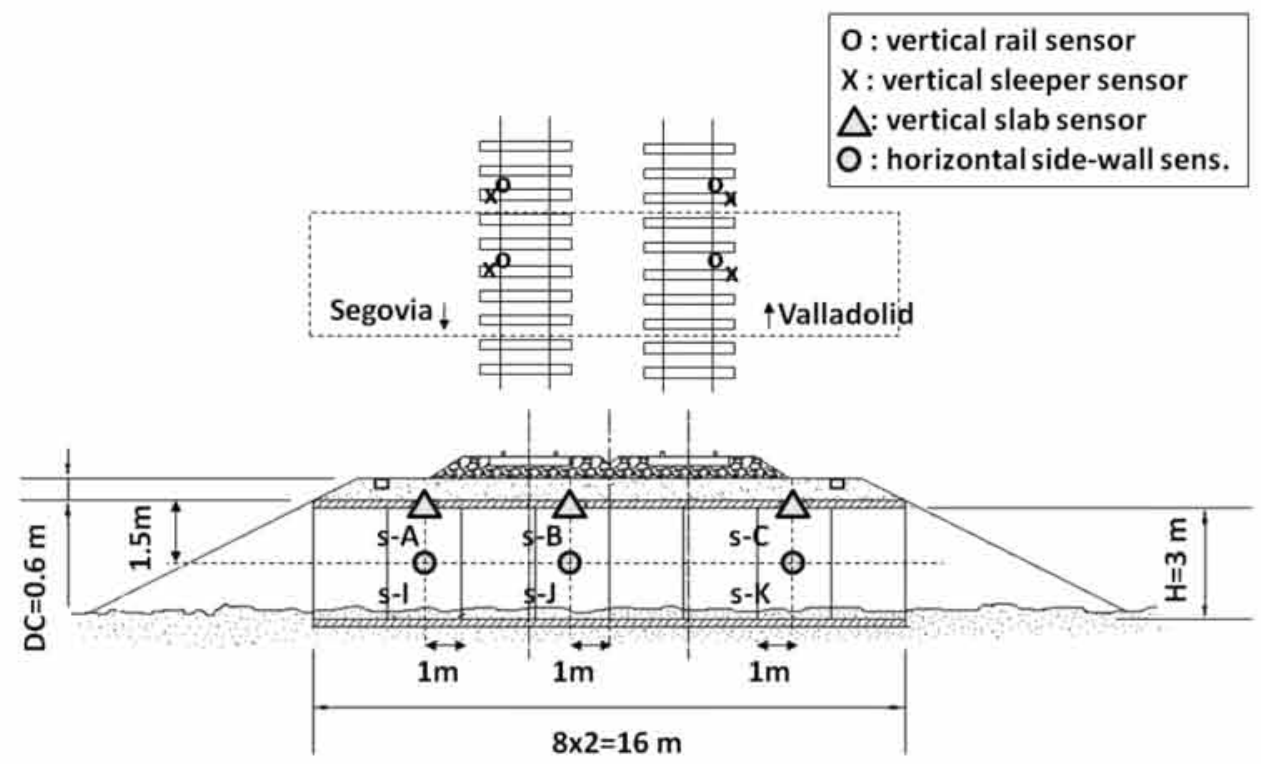

Figure 8. Structure geometry and sensor positioning. Dimensions are expressed in metres.
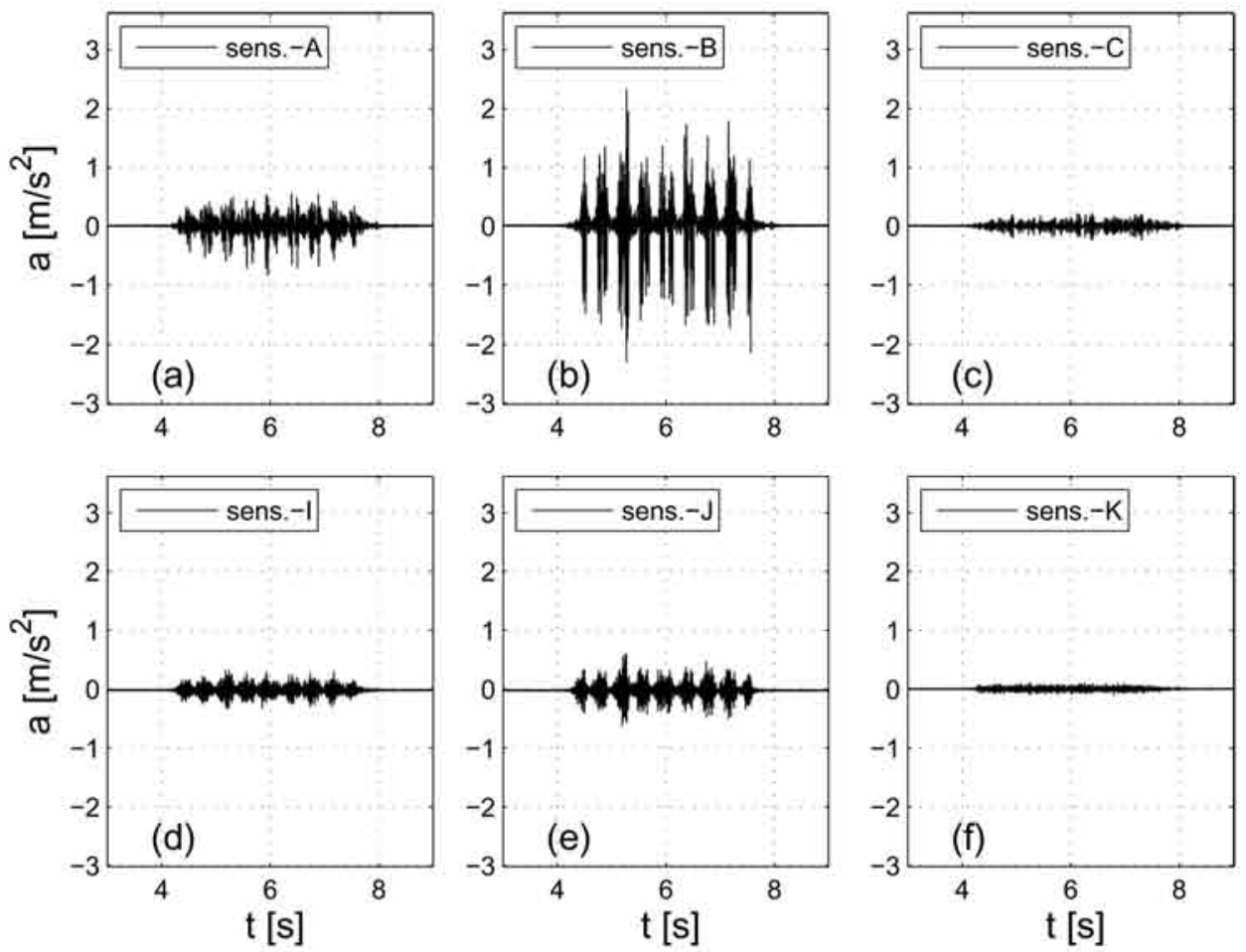

Figure 9. Sample acceleration records for sensors on the roof (plots a, b and c) and at the wall (plots d, e and f).

amounts of energy at frequencies up to $120 \mathrm{~Hz}$. Record analysis and preliminary models have revealed that the fundamental vibration mode of the roof-slab is close to $40 \mathrm{~Hz}$. This finding is interesting because the Eurocode (EN1990-A2, 1990) indicates that peak acceleration levels must be calculated considering frequencies up to the greater of: (i) $30 \mathrm{~Hz}$; (ii) 1.5 times the frequency of the fundamental mode of vibration; (iii) The frequency of the third mode of vibration. In this case, it is difficult to establish the vibration modes of the structure-embankment ensemble. However, it is clear that there is an important amount of energy exhibited far above $1.540=60 \mathrm{~Hz}$. 
Figure 11 represents, for each sensor, all of the recorded peak acceleration values (46 trains) as a function of train speed. Different symbols are used for each train type. Also, different symbols are used for trains travelling from Segovia to Valladolid (northbound) and for those going from Valladolid to Segovia (southbound).
Interestingly, the speeds for a given train type are similar in almost all cases. This is logical, considering that these trains are almost always operated at their nominal speeds. However, even when considering each group of similar samples (i.e. a given train at a given speed), there is always a large scatter in peak acceleration values. It is also clear that the track,
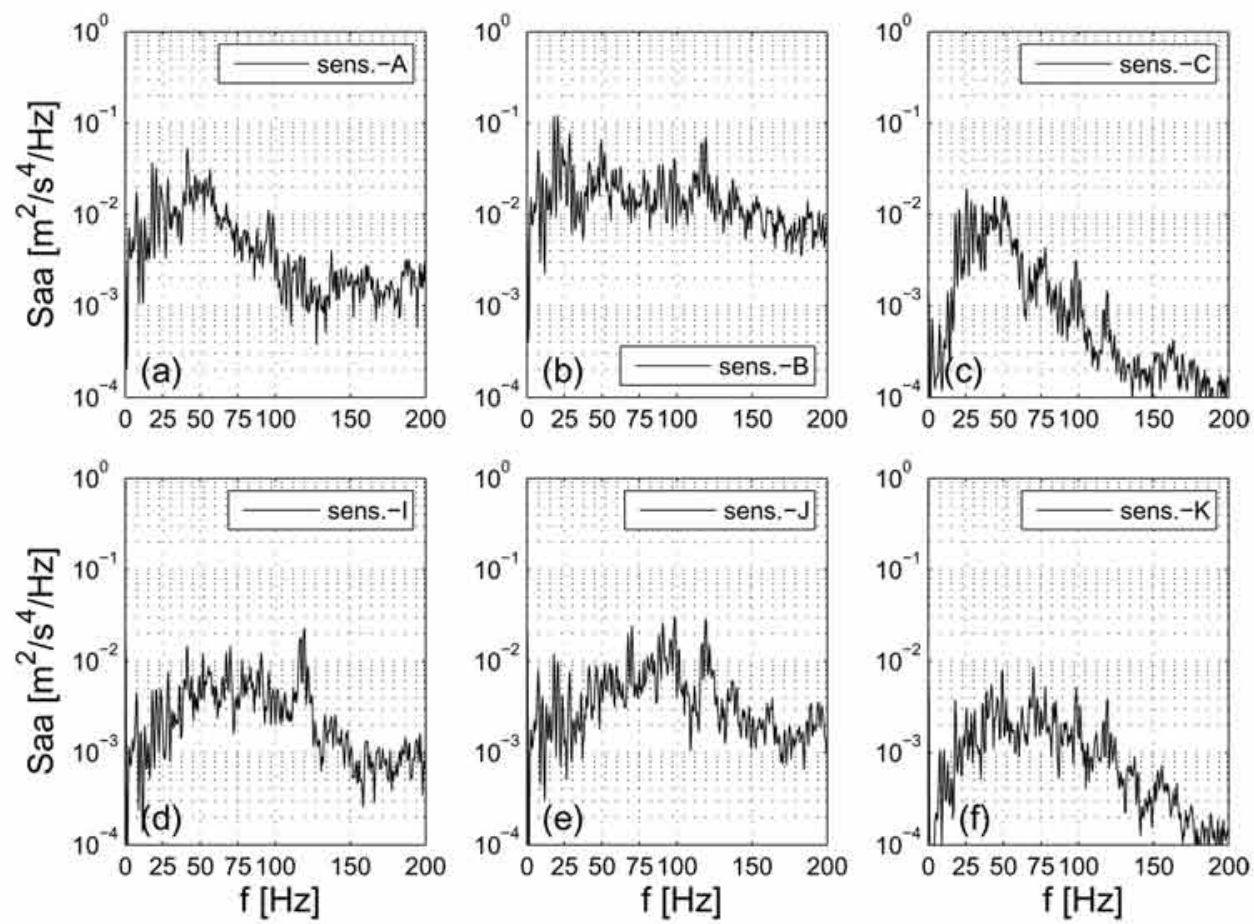

Figure 10. Spectral densities for the recording presented in Figure 9, on the roof (plots a, b and c) and at the wall (plots d, e and $f$ ).
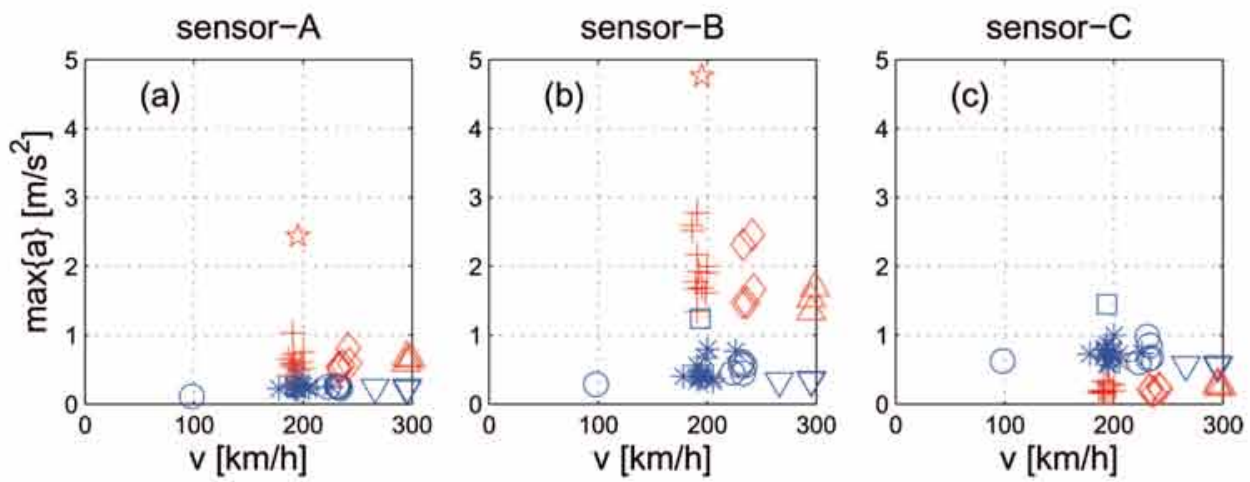

\begin{tabular}{|c|c|c|}
\cline { 2 - 3 } \multicolumn{1}{c|}{} & Seg. $\rightarrow$ Vall. & Vall. $\rightarrow$ Seg. \\
\hline S-121 & $\bigcirc$ & $\diamond$ \\
\hline$S-130$ & $*$ & + \\
\hline$S-102$ & $\nabla$ & $\triangle$ \\
\hline$S-252$ & $\square$ & \\
\hline
\end{tabular}

Figure 11. Peak accelerations on the roof: (a) sensor A, (b) sensor B and (c) sensor C. 
represented by different colours in Figure 11, is important for the response level, but this difference can be explained by the spatial load distribution arising from the plate effect of the roof-slab.

Depending on the direction of travel, the relative distances between the sensor and the occupied track are different. Measurements obtained from both directions of travel can be used together if this relative distance is considered. As shown in Figure 12, when considering relative distances, the number of available positions for comparison increases because the central sensor is not placed symmetrically.

Figure 13 presents a plot of peak vertical acceleration as a function of relative sensor position along the roof-slab of the underpass. To reduce all other sources of scatter, only S-130 trains travelling at approximately $200 \mathrm{~km} / \mathrm{h}$ were considered. The colours and symbols used are consistent with those in Figure 11. From Figure 13, for example, it is clear that at positions of $5 \mathrm{~m}$, both directions of travel led to similar acceleration levels, which confirms the importance of relative position in explaining the response values.

Figure 13 shows the unequal distribution of acceleration responses along the longitudinal (perpendicular to the track) cross-section of the roof-slab. The response is much greater below the occupied track than below the empty one, and the variation of the acceleration level shows the distribution arising from the plate effect of the roof-slab. Figure 13 also shows the scatter among recordings for each given train and speed. This scatter is partially caused by other parameters such as wheel roughness. However, given the highly nonlinear wheel-rail dynamics and the link between peaks in acceleration and the high-frequency content of the signal, random impacts may be responsible for most of the scatter.

The coefficient of variation $(\mathrm{CoV})$ provides a measure of this scatter. Considering only the records with highest responses, that is, recordings at the relative track-sensor position $+1 \mathrm{~m}, \mathrm{CoV}=33 \%$. If, instead of actual records, maxima are taken from running RMS values using rectangular windows with lengths equal to $1 \mathrm{~s}$, the scatter is reduced to $\mathrm{CoV}$ RMS $=15 \%$. The reason for this reduction is that running RMS values are less dependent on the veryhigh-frequency range and therefore less dependent on the nonlinearities of the problem (e.g. shocks). This scatter is similar to that previously measured for accelerations in simply supported bridges on other HSLs (Xia, Zhang, \& Gao, 2005).

\section{Global analysis}

\subsection{Acceleration distribution along the roof-slab mid span}

This section focuses on the validity, for all closed-box frames, of the conclusions that have just been drawn with reference to a particular structure. The number of available recordings (i.e. number of trains) varies depending on the structure (cf. Table 4). During the

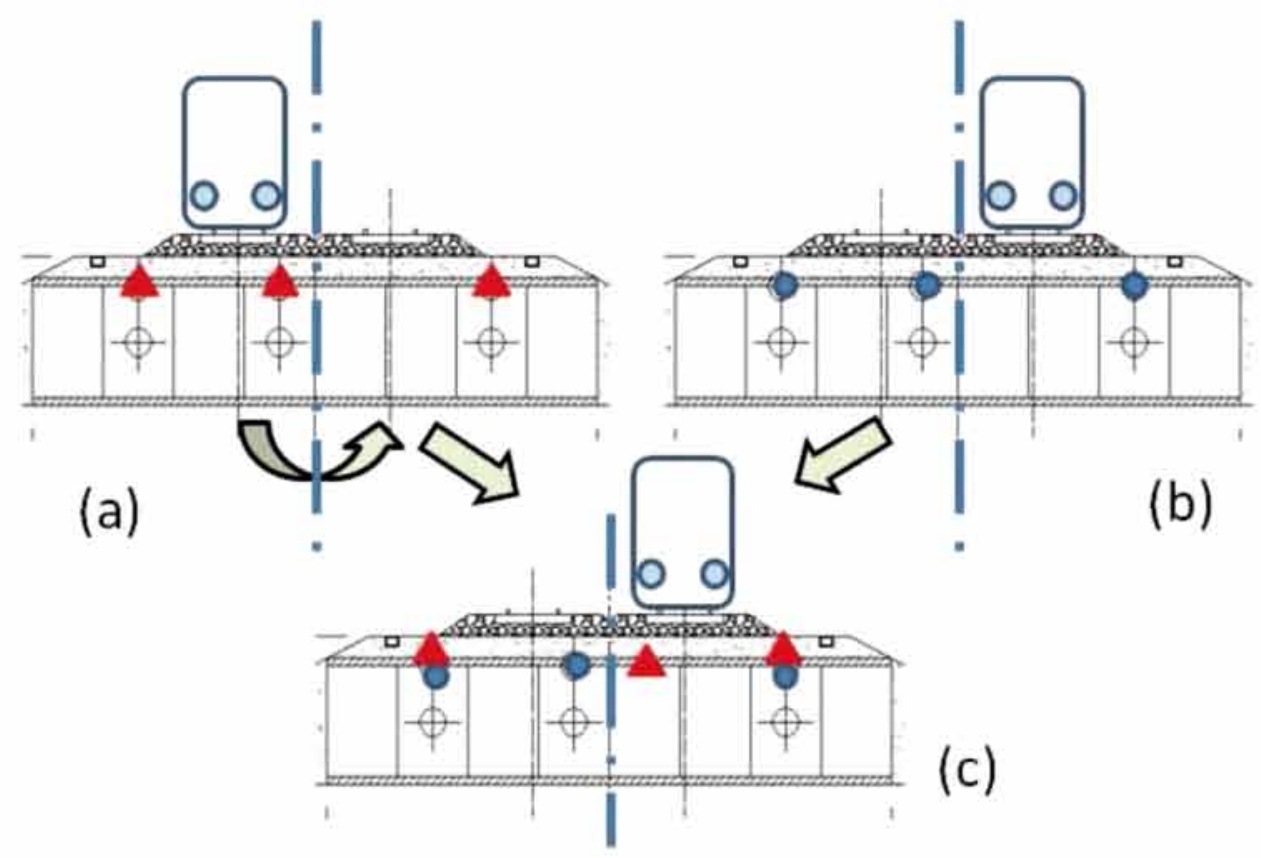

Figure 12. Identification of the relative positions of sensors with respect to the track axis for trains travelling: (a) southbound, and (b) northbound. Plot (c) shows relative positions considering a single reference track. 


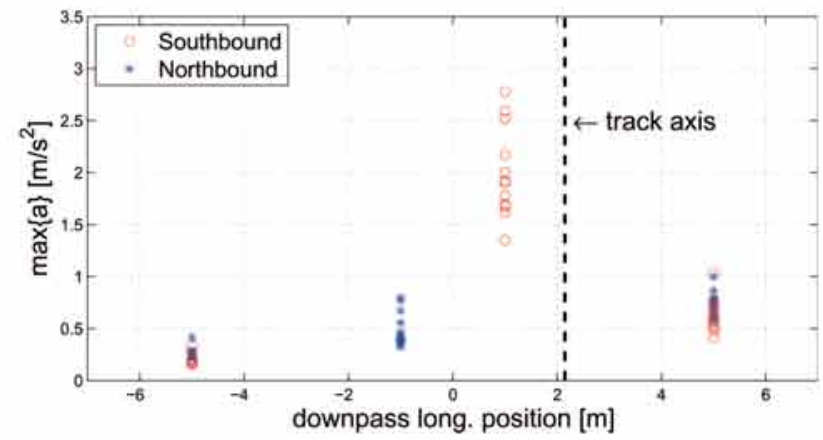

Figure 13. Peak acceleration as a function of relative position along the transverse axis of the roof (considering only S-130 trains travelling at approximately $200 \mathrm{~km} / \mathrm{h}$ ).

Table 4. Recodings available for each structure-train type pair.

\begin{tabular}{lcccccc}
\hline & & \multicolumn{5}{c}{ Number of trains } \\
\cline { 3 - 6 } Item & Dimension & S-102 & S-121 & S-130 & S-252 & Total \\
\hline$m 103$ & $2.3 \times 1.5$ & 1 & 2 & 7 & - & 10 \\
$m 023$ & $3 \times 3$ & 6 & 12 & 26 & 2 & 46 \\
$m 038$ & $3 \times 3$ & 2 & 2 & 8 & 1 & 13 \\
$m 003$ & $5 \times 3$ & - & 1 & 10 & 1 & 12 \\
$m 030$ & $8 \times 4.75$ & 2 & 2 & 6 & 1 & 11 \\
$m 044$ & $10 \times 4.45$ & 2 & 2 & 6 & 1 & 11 \\
\hline
\end{tabular}

measurements the line was far below its full capacity. Therefore, constraints linked to available day-light time and sensor placement resulted in around 10-12 recorded trains per work-day.

One of the main goals of this research project was to obtain values of structural response for a variety of structures. In the previous section it was observed that scatter in acceleration values for a given train and a given speed was of the same order as scatter due to speed alone. This applies to the six structures studied and is certainly due to the narrow range of variation in speed, as well as the similar axial loads for each train. Only S-252 trains lead to significantly higher levels.

Keeping these ideas in mind, maximum acceleration values for all structures will be presented as a function of track-sensor relative position (i.e. as shown in Figure 13), considering all trains and all speeds (Figure 14). Maximum recorded peak values are identified and listed in Table 5. In this table maximum values excluding S-252 series are also identified. As indicated before, these trains may be treated separately due to the difference in axle load.

The results displayed in Table 5 provide further evidence of the effects of some known factors. For example, it is well known that the response increases as the span decreases, or that acceleration levels decrease as the depth of cover increases. In addition to this, these results allow quantifying the effect of these factors.

Back to the distribution of peak acceleration values along the roof slab (Figure 14), it is interesting to notice that the bell type distribution appears in all cases, but its sharpness is bigger in shorter spans. This may be explained by slab stiffness, and the resulting vibration modes. In $\mathrm{m} 003(5 \times 3 \mathrm{~m})$ only measurements in one direction are presented because of the important differences in train speeds depending on the circulating sense (this particular structure was very close to Segovia station).

It is important to highlight the high acceleration values recorded for underpasses with the shorter spans. Figure 15 displays, for the sensors placed at the roofslab, one portion of the acceleration record containing the highest peak (structure m003, S-130 train at approximately $200 \mathrm{~km} / \mathrm{h}$ ). The recording from sensor A allows identifying the passage of the first seven bogies over the structure. The first two bogies belong to the head and have two axles. Then there is a transition wagon with two single-axle bogies, the second one being shared with the next wagon. All intermediate wagons have two extreme single-axle shared bogies (axle distance $13.14 \mathrm{~m}$ ).

The highest recorded value is associated with the passage of the first axle of the second bogie. Figure 15 indicates clearly that, even for the sensor with the highest acceleration values (Figure 15(a)) the highest peak is not surrounded by other peaks reaching nearly the same level. In addition to this, the peak is less pronounced at the following sensor (Figure 15(b)), and has completely vanished in the recording at the remaining sensor (Figure 15(c)). This feature suggests that shocks may be responsible for this peak.

Peak values like the one displayed in Figure 15(a) are beyond the accepted limits for ballast liquefaction or loosening (3.5 m/ $\mathrm{s}^{2}$ according to (EN1990-A2, 1990)) at a position, the lower face of the roof-slab, where acceleration values are lower than those at the ballast-embankment interface. After the completion of the measurements, a visual inspection by the owner's staff to this structure did not reveal any sign of this phenomenon. These measurements support the case against actual definition of the limit acceleration value in the Eurocode.

Shocks, due to their impulsive nature, display energy up to very high frequencies. However, models used in structural dynamic analysis usually bound the analysis to lower values. Thus, usual models would not be able to reproduce peak acceleration values listed in Table 5. In general, peaks associated to shocks do not account for an important amount of the overall energy. Therefore, in many applications it is not 

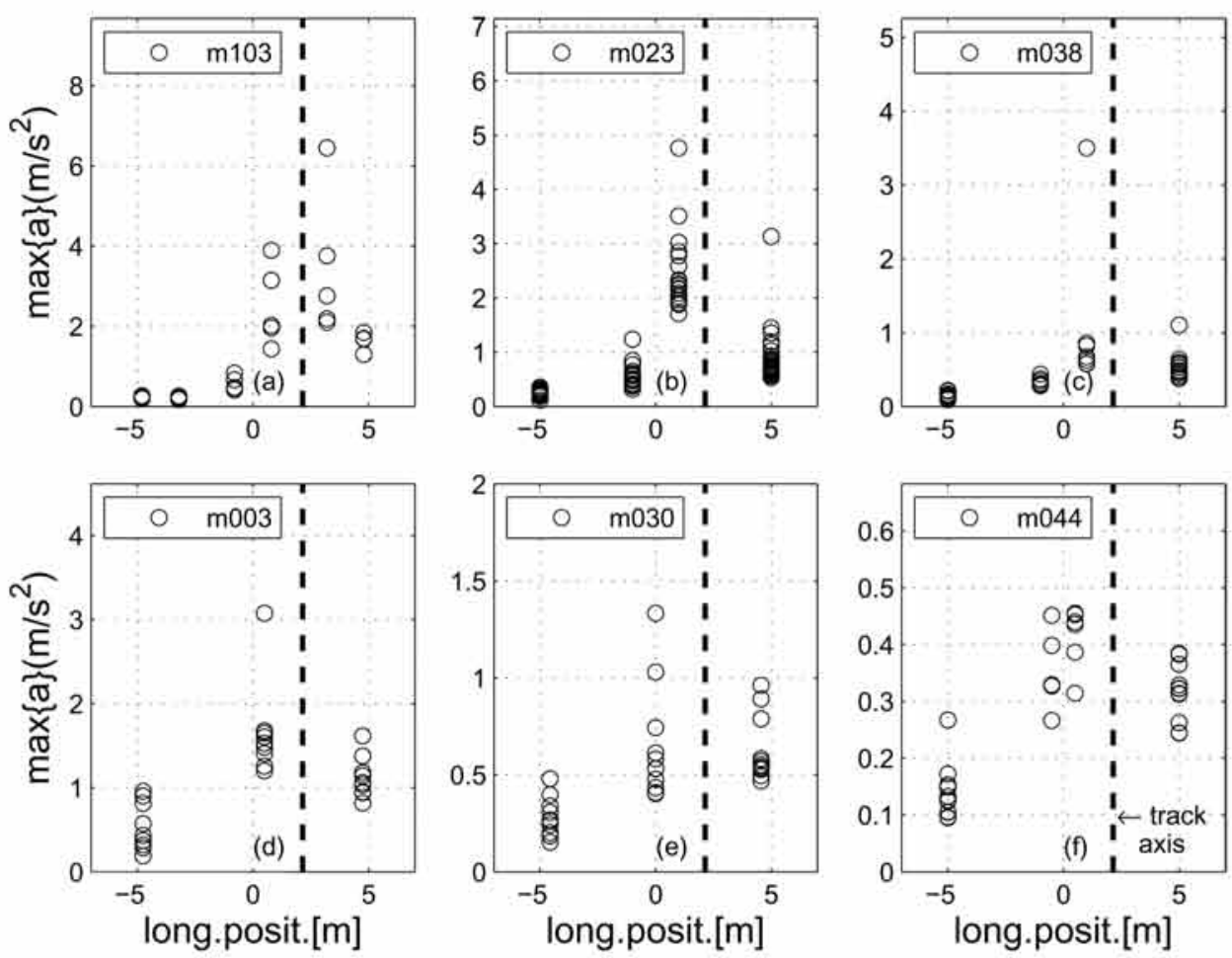

Figure 14. Peak acceleration as a function of sensor position for each frame: (a) $m 103$, (b) $m 023$, (c) $m 038$, (d) $m 103$, (e) $m 030$ and (f) $m 044$. All trains and all speeds considered, except for $m 103$ where only data from one of the two tracks are displayed.

Table 5. Maximum values of recorded peak accelerations $\left(\mathrm{m} / \mathrm{s}^{2}\right)$.

\begin{tabular}{lcllllc}
\hline Item & $m 103$ & $m 023$ & $m 038$ & $m 003$ & $m 030$ & $m 044$ \\
$\mathrm{~L} \times \mathrm{H}(\mathrm{m})$ & $2.3 \times 1.5$ & $3 \times 3$ & $3 \times 3$ & $5 \times 3$ & $8 \times 4.75$ & $10 \times 4.75$ \\
$\mathrm{DC}(\mathrm{m})$ & 0.6 & 0.6 & 3.1 & 1.0 & 1.0 & 1.15 \\
\hline All trains & 6.45 & 4.76 & 3.50 & 3.08 & 1.33 & 0.46 \\
Except & 6.45 & 3.51 & 0.86 & 1.68 & 1.03 & 0.46 \\
$\quad \mathrm{~S}-252$ & & & & & & \\
\hline
\end{tabular}

important to take them into account. Furthermore, due to their high energy content, usual models are not suited to cope with them. For this reason, comparisons between measurements and models are often performed considering running RMS values. They provide a measure of the energy content of the signal along time.

Figure 16 is analogous to Figure 14, but displaying the maximum values of the running RMS time history, instead of peak values. Running RMS acceleration histories were calculated using $1 \mathrm{~s}$ long rectangularshaped windows consistent with common practice (ISO-8041, 2005). It is clear that scatter has been much reduced compared to the former one. Now, some patterns of the dynamic behaviour of the roof-slab are revealed. For instance, in Figure 16(a), response reaches a minimum at a position approximately below the empty track.

\subsection{Frequency content of the acceleration records}

Now attention is turned to energy content. In order to identify an upper frequency limit in the energy content, the following analysis was performed. For each train, the central roof-slab sensor was selected. It was filtered using a Butterworth eighth-order low pass filters with cutoff frequency $(f c)$ stepping down from $400 \mathrm{~Hz}$ to $70 \mathrm{~Hz}$. For every filtered signal running RMS values using rectangular $1 \mathrm{~s}$ long windows were computed, then maximum values identified. Then these maximum values, normalised with the same value obtained from the non-filtered signal are plotted against corner frequency. The peak RMS values decrease with decreasing $f c$ values since increasing amounts of energy are being eliminated from the signals. Therefore, these plots provide a measure of the relative amount of energy beyond the corner frequency.

These plots are presented in Figure 17 for all frames. It is clear that, except structure $\mathrm{m} 103$, in all cases the energy content is important until around $120-150 \mathrm{~Hz}$ depending on the structure. Thus, dynamic simulations should take frequencies up to this range into account. Or perhaps the frequency bound 

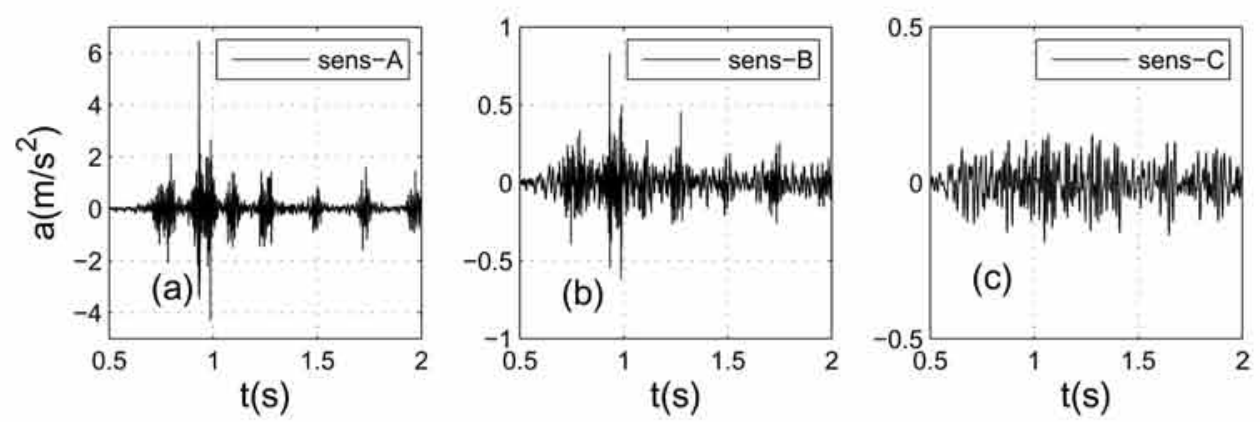

Figure 15. Record with highest peak acceleration recorded at sensors: (a) A, (b) B and (c) C. Structure $m 003$, S-130 train, 200 $\mathrm{km} / \mathrm{h}$.
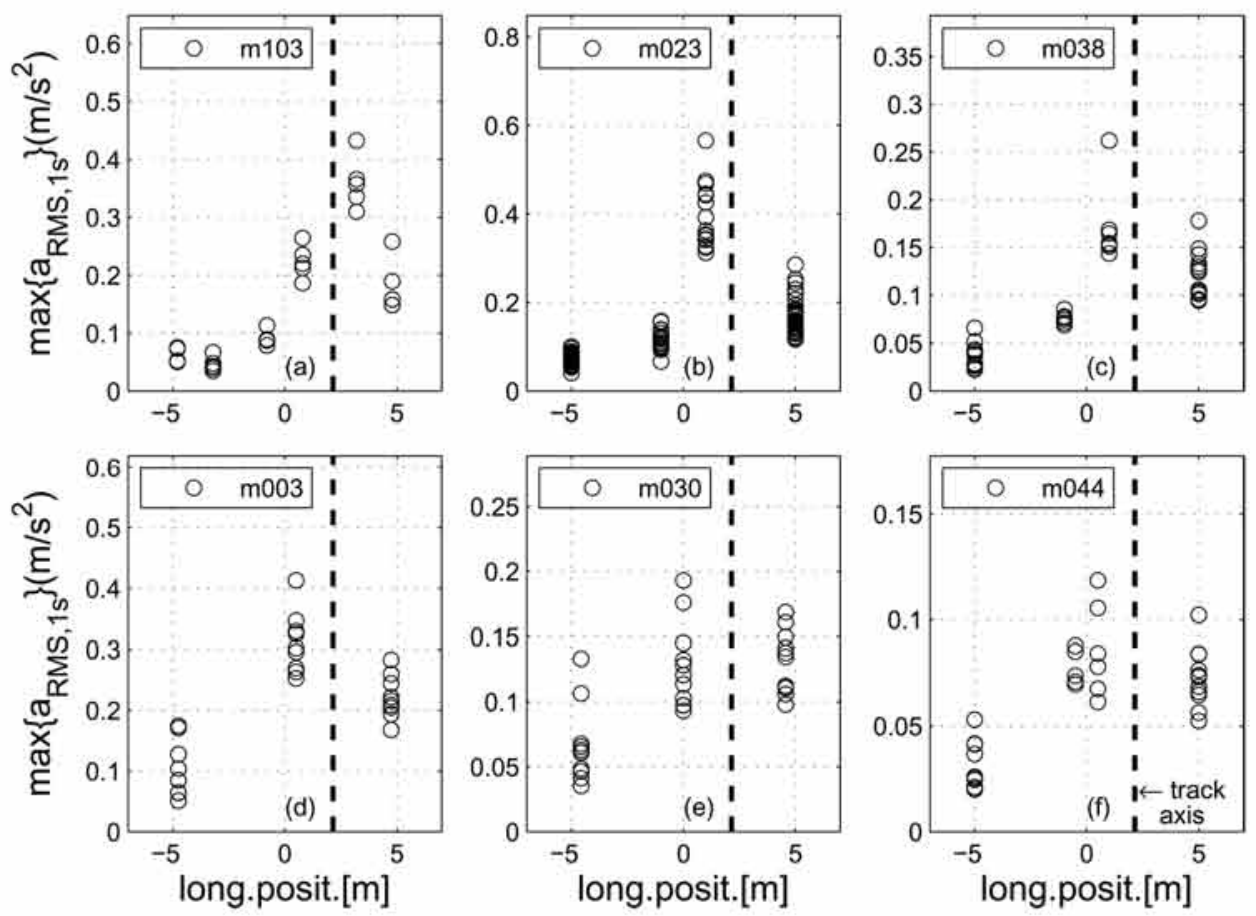

Figure 16. Root mean square acceleration as a function of sensor position for each frame: (a) $m 103$, (b) $m 023$, (c) $m 038$, (d) $m 003$, (e) $m 030$ and (f) $m 044$. All trains and all speeds considered, except for $m 003$ where only data from one sense of circulation are displayed.

should be fixed by setting a lower limit to the amount of energy that has to be considered $(90 \%$ of the energy for instance). The importance of the energy content of relatively higher frequencies in the case of the structure with the shortest span-length (m103, Figure 17(a)), is the result of its higher modal frequencies. Around 15$20 \%$ of the energy of the signals lay above $200 \mathrm{~Hz}$. There is one exception (the upper curve), that can be explained by the relatively low speed of the train (100 $\mathrm{km} / \mathrm{h}$ instead of $200-250 \mathrm{~km} / \mathrm{h}$ ).

\subsection{A heuristic rule to estimate acceleration levels}

The analysis of a particular structure in section 4 draws two interesting conclusions. First, the distribution of maximum recorded values along the roof slab midspan is bell shaped. And second, in the range of usual operation speeds, the peak recorded acceleration values during the passage of the same train at the same speed display such a scatter that the effect of train speed is hidden. Also, previously in this section, it was concluded that trains having similar axle loads result in similar acceleration levels.

The two latter conclusions suggest that, for the purposes of estimating average peak acceleration values for any given structure, all speeds and all trains with similar axle loads might be considered together. In order to synthesise the results, an empirical rule that could guide future designers has been looked after through regression on selected geometrical properties 

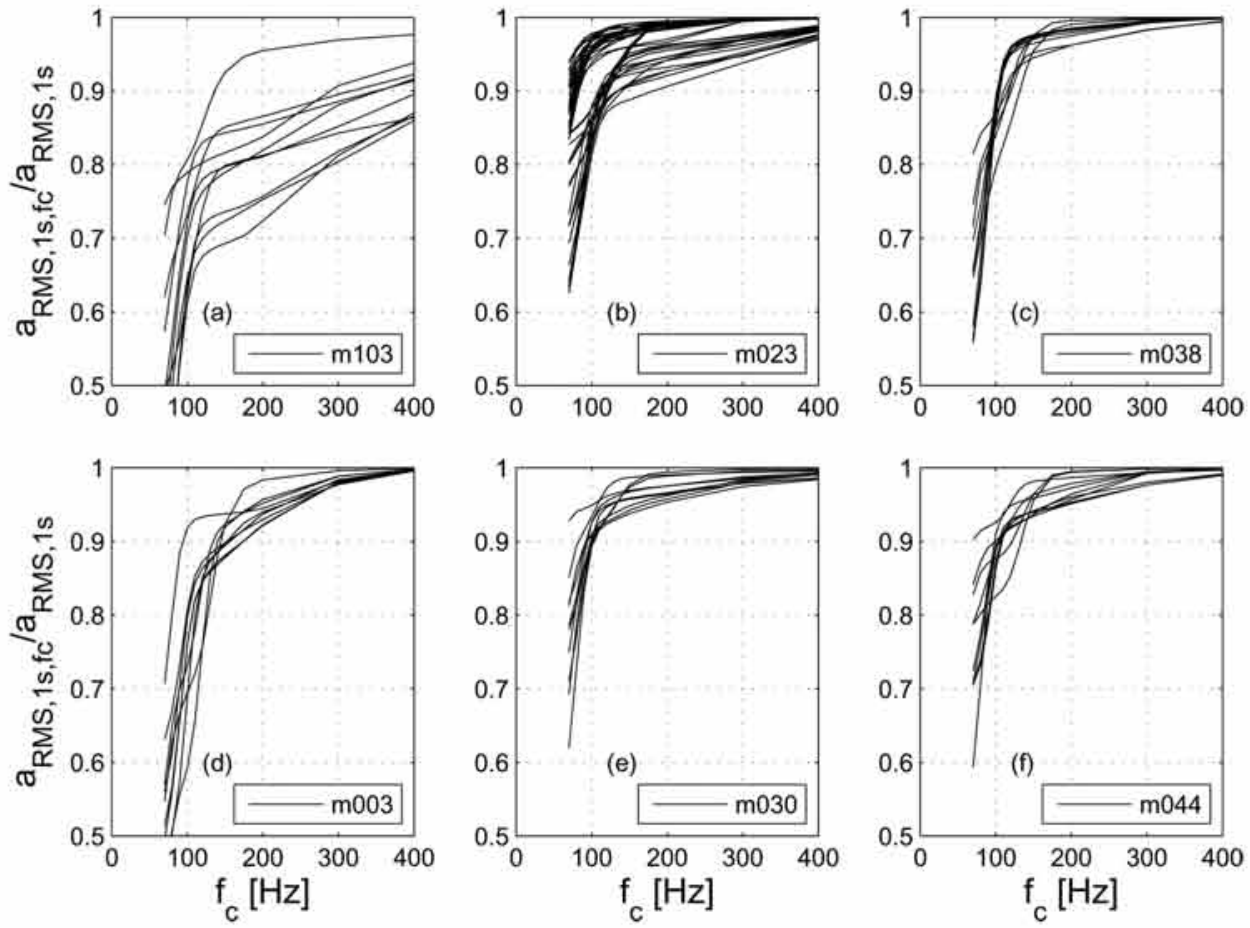

Figure 17. Peak RMS value as a function of the corner frequency of the low pass filter applied to the signal.

of the structure. As values vary along the roof slab mid span, the formula will refer to values at the point displaying the highest response value. Since such a position is not available, the heuristic rule is obtained from scratch following a two-step procedure. First, acceleration at the points under highest demand is estimated using the measured values for each frame. Then, the heuristic rule is obtained through regression, taking into account the key geometrical parameters.

As indicated before, peak acceleration values are usually associated with shocks and therefore display more scatter than maximum values of RMS acceleration records. For this reason in this section the latter will be used to extract the rule. The distribution of maximum recorded values along the roof-slab mid span (cf. Figures 14 and 16) suggests a distribution as follows.

$$
\begin{aligned}
& \max \left\{a_{\mathrm{RMS}}(x)\right\} \\
& =a_{0}+a_{1}\left(x-x_{\min }\right)+\frac{a_{2}}{\sigma \sqrt{2 \pi}} \exp \left\{-\left[\frac{x-\mu^{2}}{\sigma}\right]\right\}
\end{aligned}
$$

where $\mu, \sigma, a_{1}, a_{2}$ and $a_{3}$ are the parameters to be fitted using the set of measurements on a structure.

The combination of a bell-shaped function with a translation and a rotation, tries to reproduce the effect, along the mid span line, of an asymmetric loading on the roof slab. Although several bell-shaped functions were tried, keeping in mind the objectives of the approach, we finally selected the well-known Gaussian distribution, and also assigned $\mu$ a value equal to half the distance between track axes. Figure 18 presents the results obtained after the adjustment along with the data from each frame.

Equation (1) might be considered as a rule enabling to assess the maximum values likely to have occurred during the passage of each recorded train in the section under the highest demand. The formula is applied to all the train excepting S-252 ones. All six trains display standard operating speeds. With these values the second step (i.e. the regression) is done. As indicated before, the train speed will not be an explanatory variable in the regression. Many combinations of geometrical and material properties have been analysed. The best fit, has been found using two variables: span length $(L)$ and the ratio between the equivalent thickness of the roof slab and the span length $\left(t_{e q} / L\right)$.

The roof slab equivalent thicknes $\left(t_{\mathrm{eq}}\right)$ results from considering the composite section made up with the roof slab and the soil overburden. Its value is proportional to its stiffness, and it is a value meaningful for designers (regardless of the depth of cover, usually roof slab thickness is close to 0.1 times its span). In all frames, the overburden has been assigned the following material properties: shear wave velocity $250 \mathrm{~m} / \mathrm{s}$, density $1800 \mathrm{~kg} / \mathrm{m}^{3}$, Poisson coefficient 0.3 . Also in all cases, concrete is supposed to be $\mathrm{C} 35$.

The regression results are summarised in Equation (2). This formula provides an easy estimation of the 
maximum RMS acceleration values likely to be found for a given geometry and material properties. As indicated before, the formula applies for trains with axle loads close to $18 \mathrm{kN}$, at standard (operating) speeds.

$$
\max \left\{a_{\mathrm{RMS}}\right\}=\exp \left[0.65-4.92 \frac{t_{\mathrm{eq}}}{L}-0.26 L\right]
$$

The predictions of Equation (2) for each frame are presented in Figure 19 together with the corrected (i.e. using Equation (1) adjusted) measured values. Two plane views are presented. In each plots some iso lines are also depicted in order to provide a sense of the surface resulting from Equation (2).
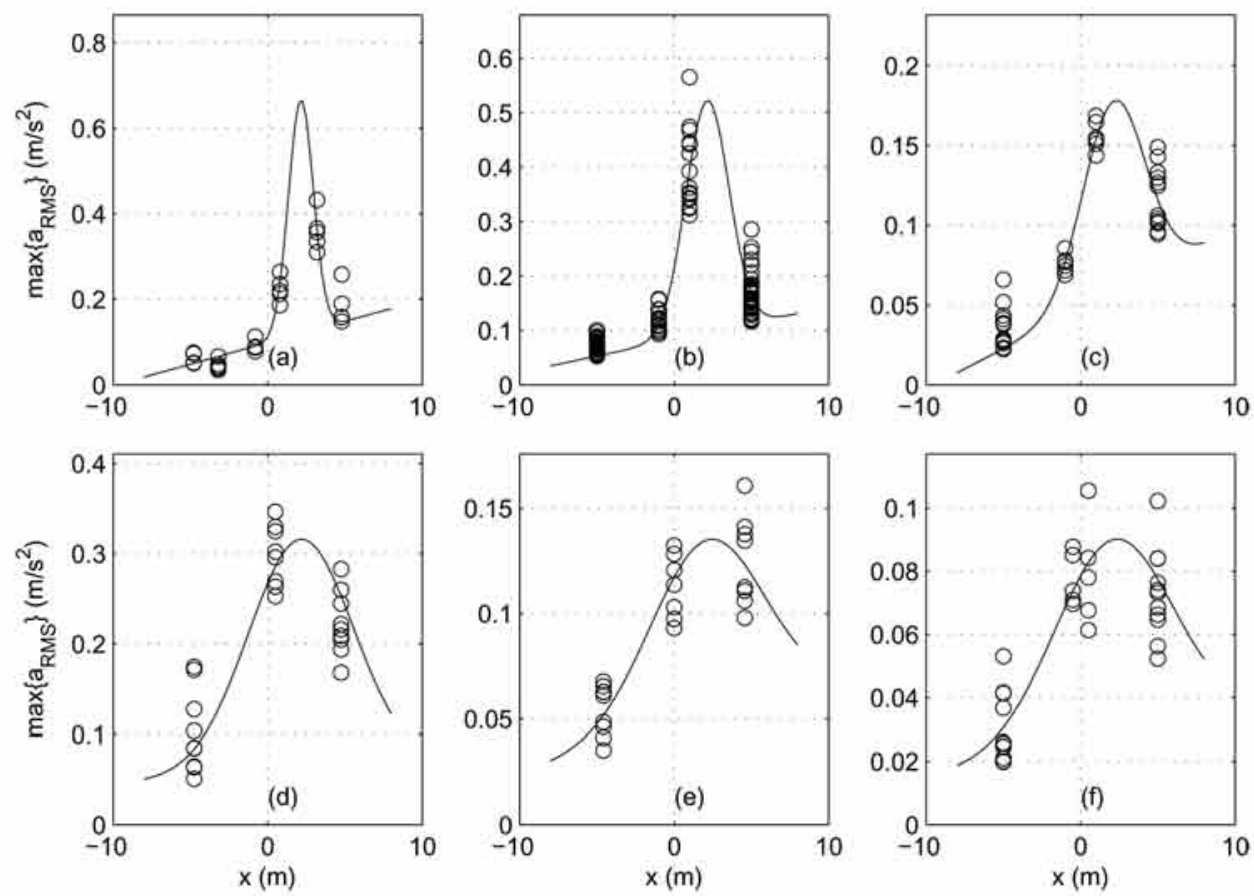

Figure 18. Maximum recorded RMS acceleration as a function of sensor position for each frame, together with the estimated average values: (a) $m 103$, (b) $m 023$, (c) $m 038$, (d) $m 003$, (e) $m 030$ and (f) $m 044$.
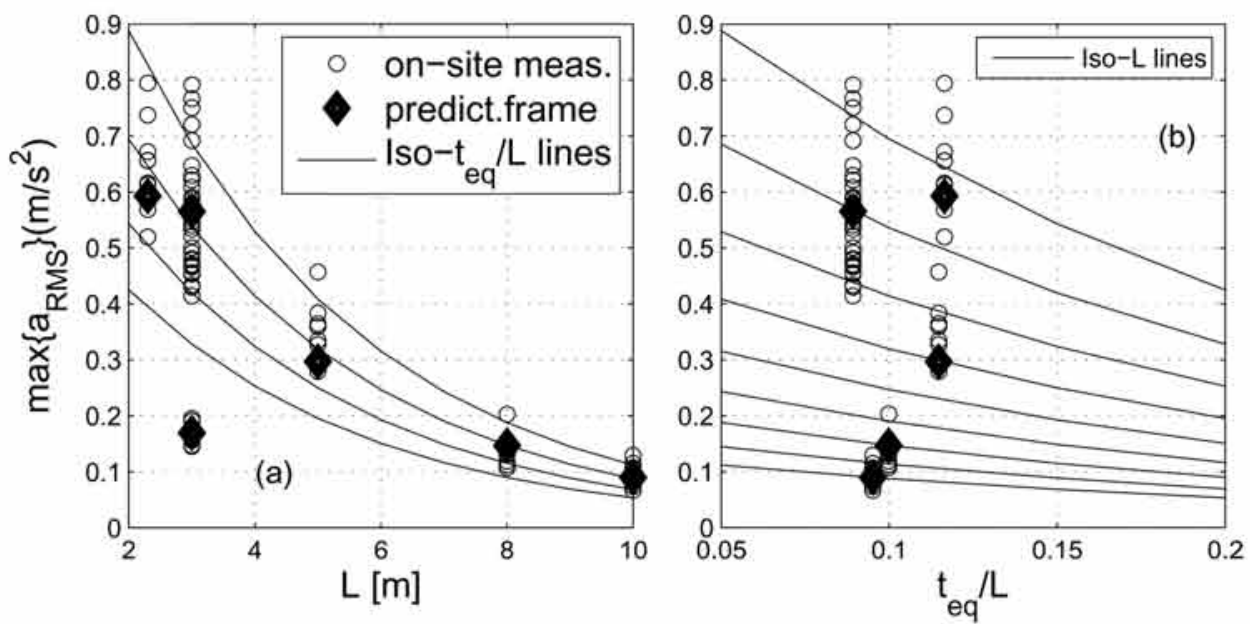

Figure 19. Estimated maximum RMS acceleration values at the roof slab mid span point under the highest together with predictions, as a function of: (a) span length, (b) $\frac{t_{\text {eq }}}{L}$. 


\section{Conclusions}

This work presents a set of onsite measurements performed on underpasses belonging to the HSL linking Segovia and Valladolid. A set of six boxframe structures were selected after analysing the geometrical characteristics of all structures in the line. The dynamic response of these structures was monitored using accelerometers during the passage of trains at speeds ranging between 200 and $300 \mathrm{~km} / \mathrm{h}$.

The results presented may provide researchers and designers with the reference values they need. Measured peak values may be used to roughly assess the expected maximum values while preparing on site measurements. Depending on the models used, either maximum actual or average values may be useful in model fitting. The results may also allow assessing the importance of some factors that are known to influence the dynamic response of underpasses. For example, acceleration levels are known to be higher for shorter spans, while the depth of cover is known to reduce the recorded acceleration.

In addition to the measured values, a regression has been obtained that allows obtaining rough estimates for any given geometry and material properties.

The analysis of the measurements has led to interesting conclusions. First, the recorded accelerations display important amounts of energy up to 120 $150 \mathrm{~Hz}$, while the current practice (EN1991-P2 2002) establishes a cut-off frequency of $30 \mathrm{~Hz}$. Thus, dynamic simulations should take frequencies up to this range into account, or at least convergence tests should be performed in order to reduce the amount of energy being neglected.

Second, it was found that acceleration scatter may be very important. The same train type at the same speed may result in quite different peak acceleration values at the underpass roof-slab. Even smoothed signals have significant scatter. Thus, it seems pointless to select one record and look after a finetuned model, because it would only be suited for this particular event. Therefore, modellers face two choices: either use deterministic mean models (fitting mean values) or use models having random parameters that should be able to produce results with similar scatter.

Third, when planning a monitoring scheme, sensors should be placed in the top slab keeping in mind the importance of stress distribution in the direction perpendicular to the track. A balance with accessibility should therefore be sought because the response has been found to be very dependent on track-sensor position, with the highest demand below the occupied track (cf. Figure 14).

\section{Acknowledgements}

This research was sponsored by Spanish Ministerio de Fomento, Direccion General de Ferrocarriles, under contract No. A-V-ENC-E-119, and was supervised by Eng. Julian Santos and Eng. Antonio Corral, to whom the authors wish to express their gratitude. 